\title{
AVALIAÇÃO DO DESGASTE EM CIRCUITOS DE MOAGEM ALIMENTADOS COM PRODUTOS DE PRÉ- CONCENTRAÇÃO DE MINÉRIOS DE VANÁDIO E COBRE*
}

\author{
Bianca Harue Ueharar ${ }^{1}$ \\ Bruno Henrique Mota Moreira² \\ Dimas José Neto $^{3}$ \\ Maurício Guimarães Bergerman ${ }^{4}$
}

Resumo

Os métodos de pré-concentração, dentre os quais podemos destacar o gravimétrico, magnético, peneiramento e ore sorting, eliminam grande parte da massa a ser alimentada na usina, o que consequentemente impacta nas características do material que irá alimentar a moagem. Assim, este trabalho busca fazer uma comparação no desgaste de circuitos de moagem com e sem a pré-concentração em minérios de baixo teor. Através de ensaios laboratoriais de Al de Bond, foi obtido o valor da abrasividade e com isso é possível estimar o consumo de material de desgaste e revestimento dos circuitos. O estudo indica que o resultado é benéfico pois, eliminando-se mais da metade da massa, o desgaste dos equipamentos decai de forma proporcional, com um ganho maior no caso do ensaio em que a abrasividade do material pré-concentrado é menor. Portanto, do ponto de vista econômico, além da pré-concentração ter baixo custo operacional, a redução nos gastos com revestimento e bolas na moagem diminui de forma muito significativa.

Palavras-chave: Pré-concentração; Minério de Baixo Teor; Desgaste em Circuito de Moagem.

\section{THE EVALUATION OF ENERGY CONSUMPTION AND WEAR ON GRINDIND CIRCUITS FED WITH PRE-CONCENTRATION PRODUCTS}

\section{Abstract}

Pre-concentration methods, which include gravimetric, magnetic, sieving and ore sorting, eliminates a large mass amount immediately after crushing, which consequently impacts the characteristics of the material that will feed the milling process. Thus, this article aims to make a comparison in milling circuits wear with and without pre-concentration method in low grade ores. By laboratory tests of Bond $\mathrm{Al}$, the value of the Abrasiveness Index (Al) was obtained. With this value is possible to estimate the consumption of the wear material and the wear in the circuit coating . The result of this study shows that pre-concentration is beneficial because eliminating more than half of the mass the wear of the equipment decreases proportionally, with a greater gain in the test that the abrasiveness of the preconcentrated material is smaller. Therefore, from an economic point of view, the preconcentration have a low operation cost and reduces the costs with coating and balls in the milling process in a very significant way.

Keywords: Pre-concentration; Low Grade Ore; Milling Circuit Wear.

1 Engenharia de Minas, estudante, Departamento de Engenharia de Minas e Petróleo, Escola Politécnica da Universidade de São Paulo, São Paulo - SP, Brasil.

2 Engenharia de Minas, estudante, Departamento de Engenharia de Minas e Petróleo, Escola Politécnica da Universidade de São Paulo, São Paulo - SP, Brasil.

3 Engenharia de Minas, estudante de mestrado, Departamento de Engenharia de Minas e Petróleo, Escola Politécnica da Universidade de São Paulo, São Paulo - SP, Brasil.

4 Engenharia de Minas, doutor, professor, Departamento de Engenharia de Minas e Petróleo, Escola Politécnica da Universidade de São Paulo, São Paulo - SP, Brasil. 


\section{INTRODUÇÃO}

Com a exploração contínua de minérios ao longo do tempo, e consequentemente a queda dos teores dos minérios disponíveis que apresentam maior complexidade, tem se tornado cada vez mais necessárias operações mais complexas de cominuição e concentração na indústria mineral, aumentando os custos de instalação e operação da usina.

A pré-concentração é uma alternativa atrativa para minimizar esses problemas, pois seus métodos servem para eliminar quantidade significativa de massa com baixa ou nenhuma quantidade de minério antes da alimentação da usina de beneficiamento, ou seja, parte da ganga é liberada em granulometria grosseira reduzindo, portanto, os impactos ambientais e a massa a ser processada nas etapas seguintes de operação, como a quantidade de material alimentada em moinho.

Os métodos de pré-concentração mais comuns são: beneficiamento gravimétrico, separador magnético, peneiramento e ore sorting. Os métodos gravimétricos são importantes economicamente devido ao seu baixo custo operacional e investimento de instalação [1]. Sua operação consiste na concentração de minerais movendo-se em seus diferentes pesos específicos. Pode-se dizer que a jigagem é a operação mais barata atualmente e separação em meio denso é o método gravimétrico de maior precisão de corte, razões pelas quais são os principais processos de operação. Das variedades de jigues no mercado, o Inline Pressure Jig (IPJ) é um dos utilizados na pré-concentração [2].

A abrasividade das rochas é um fator de considerável influência no desgaste dos equipamentos de beneficiamento mineral. $O$ ensaio de abrasividade de Bond quantifica o índice de abrasividade de um minério [3]. Pode ser utilizado para calcular o desgaste de revestimento em britadores e moinhos e consumo de bolas e barras em moinhos [4]. Removendo a ganga na pré-concentração, remove-se grande parte da massa que, geralmente, apresenta um WI e Al mais elevado do que o mineral de minério, gerando ganhos adicionais ao diminuis os custos com energia e desgaste dos revestimentos. Até o momento, entretanto, há poucas pesquisas que avaliam os impactos que a exclusão da ganga por pré-concentração tem no desgaste dos revestimentos e bolas.

O presente estudo tem por objetivo investigar o desgaste em circuitos de moagem cuja a alimentação tenha passado por uma etapa de pré-concentração, prevendo os possíveis ganhos operacionais, ambientais e consequentemente econômicos. Foram estudadas amostras de uma mina de Vánádio, da empresa Vanádio de Maracás S/A [5], e amostras de cobre da empresa Caraíba, de um projeto no Pará, chamado Boa esperança.

\section{MATERIAIS E MÉTODOS}

Trabalhou-se com amostras da Mina de Vanádio e Mina de Cobre. A amostragem de magnetita-piroxenita foi feita pela equipe da mina de Vanádio, da empresa Vanádio de Maracás S/A [5], e enviadas separadamente em três amostras de alimentação, ganga e concentrado, resultado do processo da pré-concentração magnética. Já a amostra de cobre foi fornecida pela empresa Caraíba em granulometria entre $10 \mathrm{~mm}$ e $3 \mathrm{~mm}$. 


\subsection{Preparação das Amostras}

O material da mina de Vanádio foi colocado em estufa aproximadamente a $60^{\circ} \mathrm{C}$ por cerca de 24 horas, pois todos os processos seguintes foram realizados a seco. Para separar as amostras em sacos com massas menores e manter a representatividade da mesma, foram feitas pilhas de homogeneização, separando em alíquotas. Foi separado $1 \mathrm{~kg}$ das amostras 13 (alimentação), 14 (rejeito) e 15 (concentrado) para a análise granulométrica de cada uma através do peneiramento a seco. Após a análise granulométrica, todas as amostras foram peneiradas na peneira com abertura de $6,35 \mathrm{~mm}$ guardando o retido e descartando o passante. Com cada amostra (alimentação, rejeito e concentrado), foi feito uma pilha de homogeneização e, em alíquotas, colocados em sacos de $400 \mathrm{~g}$.

Com a amostra da mina de Cobre, antes foi realizada uma operação de concentração gravimétrico através de um jigue de estratificação laboratorial, fabricado pela AllJig, com o objetivo de simular uma operação de pré-concentração. $\mathrm{O}$ ensaio foi feito no Instituto de Pesquisa Tecnológicas (IPT). Foi estabelecido, através de uma válvula rotativa, 80 pulsos por minuto. A válvula que controla a pressão de ar dentro do tanque foi aberta ao máximo. O material é depositado por cima do crivo, situado a cima das bandejas que são as camadas de estratificação do jigue. O tanque é então preenchido por água até um pouco abaixo do crivo. A amplitude, calculada através de uma régua, é de $40 \mathrm{~mm}$ em todos os ensaios.

Após a jigagem, cada camada de estratificação foi retirada e colocada em uma bandeja para ser levada à estufa, por cerca de 24 horas a temperatura de $80^{\circ} \mathrm{C}$. Após retirar da estufa, a primeira gaveta foi separada como o material concentrado (material pré-concentrado), enquanto as outras gavetas foram unidas como material de rejeito (rejeito da pré-concentração). O material então foi manuseado de forma idêntica a mina de Vanádio para obter alíquotas de $400 \mathrm{~g}$.

\subsection{Ensaio de Índice de Abrasividade (Al)}

Todos os ensaios de Al, tanto para a mina de Vanádio quanto para a mina de Cobre, foram feitos da mesma forma. Os ensaios foram realizados em um abrasímetro, fabricado pela Furlan. Para fazer um ensaio de Al são necessários 4 sacos de $400 \mathrm{~g}$. A placa de aço foi limpada com álcool e pesada inicialmente. Essa placa deve ser colocada no abrasímetro e ser retirada somente depois que acabar os 4 ciclos. No intervalo de cada ciclo, que leva 15 minutos, o abrasímetro era aberto para retirar a amostra que era colocado num recipiente e mais uma alíquota de $400 \mathrm{~g}$ era colocada no moinho para o próximo ciclo. Ao término dos quatro ciclos, e após ter colocado no recipiente a amostra de dentro do abrasímetro, a placa de aço é retirada, limpada com álcool e pesada novamente para ver sua massa final [3].

Com as amostras dos 4 ciclos, que foi colocada num recipiente, é feito um peneiramento, com as aberturas: $19 \mathrm{~mm} ; 16 \mathrm{~mm} ; 12,5 \mathrm{~mm} ; 9,5 \mathrm{~mm} ; 6,35 \mathrm{~mm} ; 3,35$ $\mathrm{mm} ; 2,36 \mathrm{~mm} ; 1,7 \mathrm{~mm} ; 0,85 \mathrm{~mm}$ e $0,425 \mathrm{~mm}$. Estes produtos foram então pesados e as massas obtidas foram utilizadas para a construção da curva granulométrica.

\section{RESULTADOS E DISCUSSÃO}

\subsection{Mina de Vanádio}

A Tabela 1 ilustra os resultados de análise química e recuperações no processo de pré-concentração das amostras estudadas. 
Tabela 1. Análise química das amostras de vanádio.

\begin{tabular}{c|cc}
\hline Vanádio & $\mathrm{V}_{2} \mathrm{O}_{5}(\%)$ & $\mathrm{Fe}(\%)$ \\
Não-concentrado & $1,26 \%$ & $34,15 \%$ \\
Rejeito & $0,88 \%$ & $24,93 \%$ \\
Concentrado & $1,96 \%$ & $41,67 \%$ \\
& & \\
Rec. Metalúrigca & $55,00 \%$ & $42,70 \%$ \\
Rec. Mássica & $35,00 \%$ & \\
\hline
\end{tabular}

A amostra de Vanádio analisada, passou por um processo de separação magnética para a pré-concentração [5]. A separação magnética, neste caso, seleciona o material ferromagnético, resultando em um concentrado rico em magnetita e um rejeito rico em sílica, como mostrado na análise química. A recuperação mássica foi de $35 \%$ e a recuperação metalúrgica de $55 \%$ do Vanádio contido, resultando em uma recuperação abaixo do esperado. Deve-se ressaltar, no entanto, que esta amostra foi coletada no circuito industrial e pode representar um momento de menor eficiência do circuito, já que normalmente a recuperação em massa média da planta de acordo com Costa [5] é de $68 \%$ e a metalúrgica de aproximadamente $80 \%$.

O resultado da análise granulométrica do material da alimentação do ensaio do $\mathrm{Al}$ indicou que somente cerca de $10 \%$ do material é retido em $+12,5 \mathrm{~mm}$, portanto não foi possível realizar o ensaio de Al nos padrões de granulometria de Bond diante do material disponível. Por isso foi selecionada a granulometria mais próxima para o ensaio de $\mathrm{Al}$, peneirando as amostras com a peneira de abertura $6,35 \mathrm{~mm}$, eliminando-se o passante e preparando sub-amostras de $400 \mathrm{~g}$ com o material retido. Foram feitos 7 ensaios. Três da amostra 15 (concentrado), para verificar se os ensaios tinham resultados semelhantes, dois ensaios da amostra 13 (alimentação) e mais dois ensaios da amostra 14 (rejeito). Os resultados obtidos dos todos os ensaios de Al feitos estão representados no e na Tabela 2.

Tabela 2. Resultados do Al das amostras 13,14 e15

\begin{tabular}{ccccc}
\hline Amostra & Ensaio 1 & Ensaio 2 & Ensaio 3 & Al Médio \\
\hline 13 & 0,1156 & 0,1197 & - & 0,1176 \\
14 & 0,1112 & 0,1062 & - & 0,1087 \\
15 & 0,1234 & 0,1080 & 0,1130 & 0,1144 \\
\hline
\end{tabular}

Diante desses resultados, percebe-se que a abrasividades das amostras é praticamente a mesma. Segundo os valores de referência para o teste de abrasão de Bond, a abrasividade é considerada baixa.

Para ter uma estimativa dos impactos no circuito industrial, utilizando-se o valor do Al dos ensaios é possível fazer cálculos de correlação de Bond que prevê os desgastes baseado na taxa de desgaste em libras de desgaste de metal por kWh de energia utilizado no processo de fragmentação, como mostram as Equações (1) e (2) [4], relativas respectivamente ao cálculo para o consumo de bolas em um moinho de bolas à úmido e ao consumo de revestimento em um moinho de bolas à úmido.

$$
\begin{aligned}
& \mathrm{lb} / \mathrm{kWh}=0,35(\mathrm{Ai}-0,015)^{0,33} \\
& \mathrm{lb} / \mathrm{kWh}=0,026(\mathrm{Ai}-0,015)^{0,3}
\end{aligned}
$$


Assim, a partir das correlações de Bond e dos valores de Al médio dos ensaios é possível estimar o desgaste em revestimentos e bolas do moinho em um ano. Levando em consideração que antes da pré-concentração a alimentação do moinho de bolas à úmido é de $250 \mathrm{t} / \mathrm{h}$ com potência de $3.262 \mathrm{~kW}$, valor calculado a partir do ensaio de WI calculado por Morreira et al. [6], com a pré-concentração a alimentação passa a ser 80 t/h pois na pré-concentração foi eliminado $68 \%$ da massa (considerando o valor médiod e projeto [5]) com uma potência de $1806 \mathrm{~kW}$, para o moinho de bolas à úmido. Sob essas condições e com uma operação de 8 mil horas em um ano, os resultados obtidos estão nas Tabela 3 e Tabela 4.

Tabela 3. Consumo anual de bolas de moinho à úmido com e sem pré-concentração

\begin{tabular}{lcc}
\hline \multicolumn{3}{c}{ Consumo de bolas de moinho à úmido } \\
\hline Pré-concentração & Sem & Com \\
Consumo bolas (lb/kWh) & 0,1651 & 0,1633 \\
$\mathrm{Al}$ & 0,1176 & 0,1144 \\
Consumo de bolas (t) & 1.955 & 1.082 \\
\hline
\end{tabular}

Tabela 4. Consumo anual de revestimento de moinho à úmido com e sem pré-concentração

\begin{tabular}{lcc}
\hline \multicolumn{3}{c}{ Consumo de revestimento de moinho à úmido } \\
\hline Pré-concentração & Sem & com \\
Consumo revestimento $(\mathrm{lb} / \mathrm{kWh})$ & 0,0131 & 0,0131 \\
$\mathrm{Al}$ & 0,1176 & 0,1144 \\
Consumo de bolas $(\mathrm{t})$ & 155 & 86 \\
\hline
\end{tabular}

Com os valores obtidos nas Tabela 3 e Tabela 4 pode-se observar que em um ano o consumo de bolas no moinho passa a ser de 1.955 toneladas para 1.082 toneladas, ou seja, o consumo de bolas decai em 873 toneladas. Já o desgaste de revestimento em um moinho que antes era 155 toneladas passa a ser 68 toneladas com a pré-concentração, resultando em uma economia de 87 toneladas.

\subsection{Cobre}

Em relação ao minério de Cobre, foi feita a pré-concentração pelo método gravimétrico, através da jigagem de estratificação. A Tabela 5 ilustra os resultados de análise química e recuperações desse processo de pré-concentração. Obteve-se uma significativa concentração dos sulfetos no concentrado, com uma recuperação metalúrgica de $85 \%$ e uma recuperação em massa de apenas $44 \%$, o que mostra a boa eficiência da operação de pré-concentração. 
Tabela 5. Análise química das amostras de cobre.

\begin{tabular}{cccc}
\hline Cobre & $\mathrm{Cu}(\%)$ & $\mathrm{Fe}(\%)$ & $\mathrm{S}(\%)$ \\
\cline { 1 - 3 } Não-concentrado & $0,75 \%$ & $13,19 \%$ & $5,37 \%$ \\
Rejeito & $0,20 \%$ & $5,52 \%$ & $0,63 \%$ \\
Concentrado & $1,45 \%$ & $26,18 \%$ & $11,88 \%$ \\
& & & \\
Rec. Metalúrgica & $85,04 \%$ & & \\
Rec. Mássica & $44,27 \%$ & & \\
\hline
\end{tabular}

Inicialmente foram realizados dois ensaios de Al com amostras da alimentação, dois do rejeito e três do concentrado. Lembrando que a alimentação é o material que não foi pré-concentrado. A Tabela 6 mostra os resultados do Al desses ensaios.

Tabela 6. Resultados do Al

\begin{tabular}{ccccc}
\hline Amostra & Ensaio 1 & Ensaio 2 & Ensaio 3 & Al Médio \\
\hline Alimentação & 0,3284 & 0,3200 & - & 0,3242 \\
\hline Rejeito & 0,2908 & 0,2752 & - & 0,2830 \\
\hline Concentrado & 0,3741 & 0,3526 & 0,3067 & 0,3636 \\
\hline
\end{tabular}

Os valores dos resultados dos ensaios de Al não foi o que se esperava. Usualmente, quanto maior a presença de sílica, maior a abrasividade. Pelas características do minério estudado, cuja rocha é um granito, a quantidade de material abrasivo (silicatos) era muito menor no concentrado, logo o valor do Al do concentrado deveria dar um valor menor do que o do rejeito, no entanto, ocorreu o contrário. $O$ valor do Al do concentrado e da alimentação deu maior.

Para se entende o que ocorreu, avaliou-se o comportamento do material durante a concentração no jigue. No jigue de estratificação, o minério é submetido a pulsações ascendentes do meio de suspensão (água), onde as partículas mais leves aceleram-se muito e percorrem um trecho ascendente maior do que as partículas pesadas. Além disso, como partículas graúdas tem maior massa, logo tendem a se alojar no fundo do jigue partículas graúdas e pesadas. Por isso, a primeira gaveta tem granulometria muito maior em relação às outras gavetas e que é perceptível na análise granulométrica das amostras. Para ver como a distribuição granulométrica afeta nos resultados de Al, foram feitos mais dois ensaios. Tomando o rejeito como modelo, a preparação das amostras para o ensaio de Al da alimentação e do concentrado foram manipuladas afim de se obter uma distribuição granulométrica em mesma proporção.

Como o material foi peneirado a $+6,35 \mathrm{~mm}$ para as alíquotas de $400 \mathrm{~g}$ do ensaio de $\mathrm{Al}$, através da massa do retido simples $+9,35 \mathrm{~mm}$ e a massa do retido simples $+6,35$ $\mathrm{mm}$ e da análise granulométrica do rejeito, é possível fazer a composição como mostra a Tabela 7.

Tabela 7. Manipulação feita para o ensaio de Al

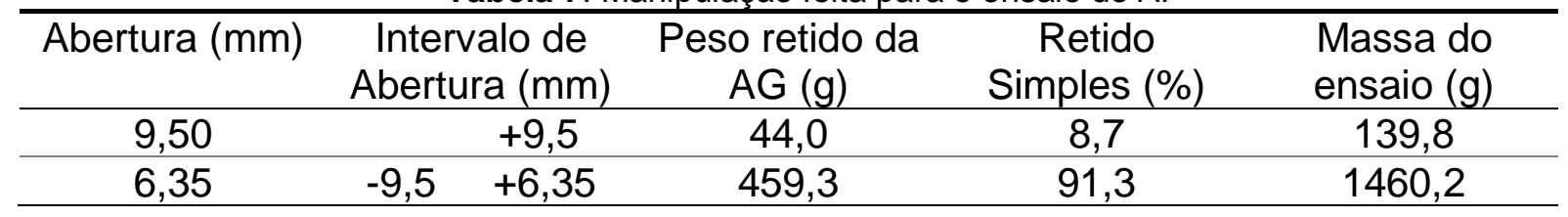


Total

503,3

100,0

1600,0

Os resultados de $\mathrm{Al}$ desses dois novos ensaios deram 0,2744 para a alimentação (Ensaio 3) e 0,3067 para o concentrado (Ensaio 4).

Comparando os três primeiros ensaios de Al do concentrado com o Ensaio 4, assim como os dois primeiros ensaios de Al da alimentação com o ensaio 3, houve uma queda nos valores do Al dos ensaios, logo, a distribuição granulométrica em que a amostra se encontra de fato influência no resultado do ensaio de Al. No entanto, segundo os valores de referência para o teste de abrasão de Bond, a abrasividade é considerada muito próxima para todos os ensaios. É necessária uma investigação mais detalhada, com informações da mineralogia, para entender por que 0 concentrado não apresentou uma abrasividade menor que a alimentação, como esperado.

Para os cálculos de consumo de consumo de corpos moedores e revestimento usando as relações propostas por Bond, foi considerado o Al desses dois últimos ensaios (ensaio 3 da alimentação e ensaio 4 do concentrado). Considerando uma alimentação de 250 t/h e potência de 3960 kW (valor calculado com WI calculado por Morreira et al. [6]) sem pré-concentração e de $110 \mathrm{t} / \mathrm{h}$ com potência de $1544 \mathrm{~kW}$ com pré-concentração gravimétrica, pois no jigue de estratificação se elimina $56 \%$ da massa, o consumo de desgaste de bolas e revestimento em um moinho de bolas a úmido que opera 8 mil horas em um ano que passa pela pré-concentração (concentrado) e que não passa (alimentação) está representado nas Tabela 8 e Tabela 9.

Tabela 8. Consumo de bolas de moinho à úmido com e sem pré-concentração

Consumo de bolas de moinho à úmido

\begin{tabular}{lcc}
\hline Pré-concentração & Sem & Com \\
Consumo bolas (lb/kWh) & 0,2242 & 0,2331 \\
Al & 0,2744 & 0,3067 \\
Consumo de bolas $(\mathrm{t})$ & 3.222 & 1.306 \\
\hline
\end{tabular}

Tabela 9. Consumo de revestimento de moinho à úmido com e sem pré-concentração

Consumo de revestimento de moinho à úmido

\begin{tabular}{lcc}
\hline Pré-concentração & Sem & Com \\
Consumo bolas (lb/kWh) & 0,0173 & 0,0179 \\
Al & 0,2744 & 0,3067 \\
Consumo de bolas $(\mathrm{t})$ & 249 & 101 \\
\hline
\end{tabular}

Com os valores obtidos nas Tabela 8 e Tabela 9, estima-se que em um ano 0 consumo total de bolas em um moinho nessa mina passa a ser de 249 toneladas para 101 toneladas com a pré-concentração, resultando em uma economia de 148 toneladas. O consumo de bolas no moinho passa a ser de 3.222 toneladas para 1.306 toneladas, ou seja, o consumo de bolas decai em 1.916 toneladas.

\section{CONCLUSÃO}


Os resultados obtidos no presente trabalho demonstram que a pré-concentração reduz o consumo de desgaste nos circuitos de moagem. Para avaliar os impactos que a pré-concentração tem no desgaste dos circuitos de moagem, foi comparado o material antes da pré-concentração, o rejeito da pré-concentração e o material préconcentrado através de ensaios de abrasividade de Bond.

Com o valor do Al desses ensaios, foi possível obter uma correlação do material gasto com a energia desprendida em determinado tempo. Dessa forma, com os valores da potência do moinho de bolas á úmido, a alimentação e o tempo de funcionamento, estima-se uma relação de quanto material será gasto em um ano.

$\mathrm{Na}$ Mina de Vanádio, os resultados dos ensaios de Al deram valores próximos, na mesma casa decimal, no entanto, o Al do pré-concentrado deu um pouco menor do que $\mathrm{o} \mathrm{Al}$ da alimentação (material não pré-concentrado), indicando que a abrasividade é menor. Apesar de ser pouca essa diferença, em proporções de um ano e eliminando $68 \%$ da massa antes da moagem, o desgaste dos equipamentos será significativamente muito menor, em um ano estima-se um gasto de 942 toneladas a menos comparado ao processo sem a pré-concentração.

No Projeto da Caraíba, o valor do Al do pré-concentrado deu maior, sendo que se esperava um valor menor já que grande parte da sílica foi eliminada na préconcentração. No entanto, devido o processo de pré-concentração utilizado (jigue de estratificação) a granulometria da amostra de concentrado é muito mais grosseira do que o de rejeito, gerando uma distribuição granulométrica muito diferente. Por isso, foram adaptados ensaios com uma granulometria composta afim de se obter a mesma distribuição granulométrica. Verificou-se que a distribuição granulométrica de fato influenciava nos resultados visto que o Al caiu com material mais fino presente. Mesmo assim, o valor do Al do concentrado continuou dando um valor um pouco maior, no entanto $56 \%$ da massa é eliminada, resultando numa economia de 2064 toneladas a menos em materiais de desgate dos moinhos em um ano com a préconcentração.

Por fim, pode-se afirmar que, do ponto de vista econômico, a pré-concentração, que tem baixo custo operacional, apresenta economias nos processos subsequentes do beneficiamento.

\section{Agradecimentos}

À bolsa de Iniciação Científica PUB (Programa Unificado de Bolsas de Estudo para Estudantes de Graduação), da Universidade de São Paulo, EDITAL 2015-2016. Ao Instituto de Pesquisas Tecnológicas por disponibilizar o jigue para o ensaio. Às empresas Vanádio de Maracás S/A e Mineração caraíba S/A por fornecer as amostras.

Agradecemos também ao CNPq pelo apoio para a realização deste estudo, por meio do Projeto Universal processo 449932-2014-1

\section{REFERÊNCIAS}

[1] CHAVES AP; CHAVES FILHO, RC. Separação Densitária. v. 6. São Paulo: Oficina de Textos,2013

[2] Gekko. Inline Pressure Jig. 2015 [acesso em 22 out. 2015]. Disponível em: http://www.gekkos.com/equipment/inline-pressure-jig.

[3] WEISS NL. SME Mineral Procesing Handbook. v. 2. New York: New York,1985. 
[4] CHAVES AP; FILHO RCC. Britagem, Peneiramento e Moagem. v. 3. São Paulo: Oficina de Textos,2012.

[5] COSTA IA. Pré-concentração magnética do magnetita-piroxenito do vanádio de Maracás S/A. Trabalho de conclusão de curso. Universidade Federal da Bahia, 2014; 82p

[6] MOREIRA BHM; UEHARA BH; JOSE NETO D; BERGERMAN MG. Avaliação do consumo de energia em circuitos de moagem alimentados com produtos de préconcentração de minérios de baixo teor. ;XXVII Encontro Nacional de Tratamento de Minérios e Metalurgia Extrativa, 2017. 